\title{
Shared decision making and patient choice for growth hormone therapy: current perspectives
}

\section{Belinda George \\ Vageesh Ayyar}

Department of Endocrinology, St. John's Medical College Hospital, Bangalore, Karnataka, India
Correspondence: Vageesh Ayyar Department of Endocrinology, St. John's Medical College \& Hospital, Kormangala, Bangalore, Karnataka 560034, India Email vagayyar@gmail.com
This article was published in the following Dove Press journal:

Research and Reports in Endocrine Disorders

9 June 2016

Number of times this article has been viewed
Abstract: Growth hormone has now been available in medical practice for close to 50 years. Its use has provided dramatic results in patients with growth hormone deficiency and it is associated with an overall favorable safety profile. Over the years, the utility of growth hormone has expanded to include treatment for short stature associated with conditions other than growth hormone deficiency, and this situation warrants greater involvement of the child and parents in the shared decision-making process. Shared decision making is in good conformance to the principle of informed consent, and it also improves the compliance and adherence to therapy as the patient fully understands the benefit and safety of the treatment. In the pediatric-care setting, the decision-making interactions usually occur between the health care provider, patient, and parents. The process may range from an autonomous decision-making pattern, where the patient or parents are fully responsible for the decision taken, to the paternalistic decision-making pattern, where the health care provider assumes full responsibility for the decision taken. However, the ideal situation is one where a truly shared decision-making process happens, in which the doctor and patient/parents work together to choose an evidence-based option, in line with the patient's preferences and wishes. The limited data available on shared decision making with regard to growth hormone replacement, however, is not very encouraging and suggests that the actual involvement of the parents as perceived by them is less than optimal. Introduction of a simple structured model for a shared decision-making process that can be easily incorporated into clinical practice and familiarization of health care providers with the same is essential to improve our shared decision-making practices.

Keywords: growth hormone deficiency, idiopathic short stature, informed decision making

\section{Introduction}

Growth hormone (GH) has a long and complex history dating back to the early 1900 s. $^{1}$ Sometime between 1920 and 1940, the growth-promoting effects of a substance derived from the anterior pituitary gland were described and demonstrated in animal models; this molecule was named the "growth hormone". The first human documented to have received therapeutic GH was a 3-1/2 year-old child with GH deficiency (GHD) in 1956; however, no metabolic effects of $\mathrm{GH}$ were seen in this patient as he received bovine $\mathrm{GH}$, and the action of GH is species-specific. The major breakthrough occurred in 1958, when Dr Maurice Raben successfully demonstrated the beneficial effects of human $\mathrm{GH}$ in a 17-year-old patient suffering from GHD. ${ }^{2}$ As the GH had to be extracted from human cadaveric pituitaries, and as the yield obtained from the extraction process in 
Table I Conditions approved for GH therapy

\begin{tabular}{ll}
\hline Year of approval & Medical condition \\
\hline 1985 & Growth hormone deficiency - children \\
1993 & Chronic renal failure \\
1996 & Growth hormone deficiency - adult \\
1997 & Turner syndrome \\
2000 & Prader-Willi syndrome \\
2001 & Small for gestational age with poor catch-up growth \\
2003 & Idiopathic short stature \\
2006 & SHOX - haploinsufficiency \\
2007 & Noonan syndrome \\
\hline
\end{tabular}

Abbreviations: GH, growth hormone; SHOX, short stature homeobox.

the early years was poor, there was severe shortage of $\mathrm{GH}$ supply, which led to the opening of pituitary black markets. With the development of recombinant human GH in the early 1980s, it was possible to freely obtain GH for experimental studies. The year 1985 was an explosive year in the history of GH, as it was then that the first case of Creutzfeldt-Jakob disease from human cadaveric GH was reported. This also coincided with the initial reports of efficacy of the human recombinant GH. This led to the US Food and Drug Administration approval of the recombinant $\mathrm{GH}$ along with banning of the cadaveric GH. Since then, the indications for using $\mathrm{GH}$ as a growth-promoting agent have expanded to include conditions other than GHD (Table 1).

\section{Issues specific for $\mathbf{G H}$ therapy}

It is well recognized that patients with severe GHD require GH replacement throughout their life and that early initiation of replacement therapy is associated with better outcomes in terms of final adult height achieved. ${ }^{3}$ There is no debate regarding the beneficial role of GH therapy in patients with GHD. Apart from the obvious improvement with regard to the final height and the associated psychological benefits, recent reports have suggested that there may also be memory and cognitive benefits, specifically in children with GHD. It has been shown based on both experimental animal models and functional magnetic resonance imaging and volumetric imaging in GH-deficient children, that specific structures such as the splenium of the corpus callosum and the right hippocampus are affected leading to impairment in cognition. Well-designed studies of both cognitive function and functional magnetic resonance imaging are needed to quantify the effects of the GH replacement therapy on these specific defects. Overall, any child found to have GHD on evaluation for short stature is likely to reap more benefits than harm, and should be encouraged to consider GH replacement. However, in children with short stature not related to GHD, the evidence is not so convincing. In fact, there is an ongoing debate regarding the justification of using $\mathrm{GH}$ for height augmentation in these patients. Hence, it is important to balance the costbenefit ratio and ensure that the patient or parent takes a well-informed decision regarding GH therapy. The process of shared decision-making assumes immense importance in these patients (non-GHD short stature).

GH replacement is currently delivered via the subcutaneous route as a self-administered injection taken at home. There are different companies producing and marketing $\mathrm{GH}$ under different brand names, with some using pen devices with prefilled GH vials, and others using the lyophilized powder that needs reconstitution before use. The concentration and injection volume may differ slightly between brands, but the important differences that add to the cost are the type of medical devices used (pen with prefilled $\mathrm{GH}$ vs powder form that needs reconstitution). Each brand also provides its own instructions-for-use leaflet, which covers preparation, storage, injection technique, and service program provided by the company. Daily injections may be perceived as a burden by the children; improved devices with needle pen injectors or needle-free delivery systems designed to minimize the pain and discomfort are often preferred by children. ${ }^{4}$

Once initiated on GH therapy, close monitoring by the health care professional is necessary for both efficacy and safety, and this means that frequent visits to the clinic are necessary, usually, once in 3-6 months. ${ }^{5}$ These frequent medical visits, along with repeated blood testing and X-ray taking, have also been known to cause considerable distress and fear in children, leading to the possibility of poor adherence. Skipping of injections is not followed by any immediate effect; positive effects are also difficult for the child and parent to appreciate, especially in cases of non-GHD conditions being treated with GH therapy. The patient's and parent's perception of treatment benefit may play an important role in acceptance of the doctor's recommendation and also in continuing the GH therapy with adequate adherence. ${ }^{6}$ It is important for the health care provider to understand parental perceptions and beliefs regarding the illness and the treatment, as this will help to support them in a better way.

\section{Shared decision making}

Shared decision making in the field of medicine is particularly important for considering treatment options in nonemergency and chronic conditions, where adherence to therapy is largely dependent on the patient's belief systems and perceptions and understanding of benefits vs safety of the therapy. ${ }^{7}$ The 
process of shared decision making in these situations has been shown to be associated with improved compliance and better satisfaction with the treatment. It is also in good conformance to the principle of informed consent, where the patient is appropriately educated and counseled regarding various facets of medical intervention prior to initiating the therapy. The shared decision-making process usually involves explicit consideration of priorities and trade-offs between both the involved parties, namely, the doctor and the patient. In that sense, the patient could be compared to a consumer who is actively involved in considering various treatment options with the advice and counsel of his/her physician. ${ }^{8}$

Shared medical decisions with significant consideration to patient preferences are essential in conditions where the primary treatment outcome is linked to the quality of life. Use of GH as a therapeutic agent in adults necessitates active involvement of the patient, as this is a situation where the therapeutic intervention is not only directly linked to a subjective outcome such as general well-being of the patient, but is also an expensive option that many patients may find difficult to afford. This makes GH therapy to some extent an elective option, particularly in adults with GHD. The patient's wants and desires are often linked to the perceptions of psychological benefit that may be obtained with the treatment. Hence, while considering GH therapy in adults, patient preferences and desires are likely to play a dominant role (and overrule the classical medical risk-benefit balance) in the decision-making process. ${ }^{9}$

\section{Shared decision making in pediatrics}

As most of the patients requiring $\mathrm{GH}$ replacement therapy are likely to be children, it is important to understand and review the dynamics of shared decision making in the pediatric group. Here, there is a third party, the parent, who is also actively involved in the decision-making process. ${ }^{10}$ The decisionmaking interactions usually occur between the health care provider, patient, and the parents, and may be considered to be occurring along a spectrum. ${ }^{11}$ At one end of the spectrum is the autonomous decision-making process, where the patient or parent is fully responsible for the decision taken. At the other end of the spectrum is the paternalistic decision-making process, where the health care provider assumes full responsibility for the decision taken. The ideal process should be a truly shared decision-making process in which the doctor and patient/parent work together to choose an evidencebased option that is in line with the patient's preferences and wishes. ${ }^{12}$ This is particularly important in the case of $\mathrm{GH}$ therapy, as it is expensive and the cost-benefit ratio in terms of height gained per currency needs to be considered and individualized for every child. This could at times be a challenging and daunting task for the physician, because it is not always easy to predict the response to GH therapy accurately. The factors that usually influence the decision to treat with GH apart from efficacy and safety include out-of-the-pocket costs borne by the parents and social factors such as the child's attitude and expectations from the treatment.

Though the ideal approach would be a shared decision-making process with equal involvement from both the parent's and physician's side, it is not always feasible. In fact, sometimes, parents may not want to be part of the shared decision-making process and may prefer a paternalistic approach, stating that the doctor knows best. Sometimes, the parent may want to involve other family members (elders/ earning members) in the decision-making process. It is important to understand the role parents prefer to play in the decision-making process, so that the physician can support decision making in a family-centered care environment. ${ }^{13}$ Concepts and evidence regarding shared medical decisions from the adult care setting cannot be adapted to the child-parent-doctor scenario encountered in pediatrics. Even simple treatment decisions taken in the pediatric setup may be more complex compared to similar examples in adult medicine. The final decision is influenced by who the relevant stakeholders are and their extent of participation in the decision-making process. In the adult setting, the involved patient usually has to choose for self over others, and this influences the final decision taken. In the case of adult proxy decisions, where one has to choose for another adult patient, the patient's past decisions, behaviors, and choices can serve as a reference guide, even in the absence of an open conversation directly with the patient.

None of these are applicable in the pediatric setting. Decisions taken for others (particularly children) are likely to be different from the decisions taken for self because parents always consider the effects of lack of timely treatment intervention on the child's future. ${ }^{14}$ When the child's preferences are unknown and their decision-making capacity is limited by the young age and stage of development, parents must use their own preferences and wishes to decide on the best therapeutic intervention. As the child grows, their developmental and intellectual capacities also improve, and this is likely to increase their involvement in the decision-making process and often, they prefer to have a say in initiating or continuing their medical therapy. Also, their changing biology and behavioral patterns, particularly in the adolescent years, influence their adherence and preferences for therapy. 
Improvements in the shared decision-making process will happen only when we understand how parents make, or wish to make, medical decisions for their children. There is a growing interest on shared decision making in the pediatric age group, particularly for conditions such as GH replacement, and this has been emphasized by associations such as the American Academy of Pediatricians ${ }^{15}$ and the Institute of Medicine. ${ }^{16}$

\section{Parent's role in decision making}

In a narrative review on what is known of parent's treatment decisions by Lipstein et al, ${ }^{17}$ it was noted that most parents prefer an active role in the process of shared decision making. This review predominantly looked at studies done on children requiring cochlear implants and others with "endof-life" care situations. Parents reported higher satisfaction with a proposed shared decision-making approach compared to the paternalistic approach. They also wanted to be actively involved in the decision-making process and were more interested in a collaborative decision-making method over the autonomous or paternalistic approach. ${ }^{18,19}$ Research done on inpatient settings showed that parents were consistently interested in participating in the decision-making process and wanted to be actively involved ${ }^{20}$; however, studies in outpatient settings have yielded inconsistent results. One study showed that when addressing acute concerns in a typical outpatient visit, most parents had a passive role in the process of treatment decisions, with the paternalistic approach dominating over a shared decisionmaking process. ${ }^{21}$

Another study showed that parents have a range of approaches to the decision-making process, and that their needs and dependence on the physician may vary according to the individual parent's approach. ${ }^{22}$ For example, parents who use a logic-based approach need to hear all the information available in detail from as many sources as possible. Apart from the counsel and advice of their treating doctor, patients and parents often refer to various Internet sites offering details of the therapy being discussed. In a study done by van Dongen and Kaptein ${ }^{6}$ looking at the parent's choices and preferences with GH replacement therapy, it was shown that the treating doctor was their main source of information for the diagnosis (94\%) and for information on $\mathrm{GH}$ devices (70\%). The Internet (69\%) and patient support groups (52\%) played an important role as an alternate and additional source of information. When it came to the options regarding various devices or delivery systems, the major role of the information provider was fulfilled by the nurse $(32 \%)$.

\section{Influences on parent's decision making}

Even though the parents are the primary decision makers in the pediatric setting, this never occurs in isolation. Their decisions are influenced by a variety of factors that include the child's disease status, parent's understanding of the disease and treatment options, the economic burden to be borne by the parents, physician's advice, and other sociocultural factors. ${ }^{23}$ Prior health care experiences can have different influences on the treatment decisions taken by the parents. A study by Cox et $\mathrm{al}^{21}$ found that when faced with acute concerns during outpatient visits, parents who had lesser outpatient visits in the preceding year were likely to be more actively involved in a decision-making process. This contrasted with the inpatient setting, where parents who had recently experienced admission were more likely to be actively involved in decision making. The same holds true for chronic diseases where the parents are more likely to be involved in the decision-making process. The presence of another family member with a similar disease, exposing them to a similar experience in the past is also known to affect the parent's decision-making process. ${ }^{24}$ This phenomenon may be a reflection of the parent's better understanding of the disease over time and their increasing knowledge of the various therapeutic options. Also, in case of chronic diseases, as the child's condition changes over time, the need for intervention vs observation becomes more or less clear.

The recommendation of the treating physician definitely plays a major role in the final decision taken. Several studies have shown that be it in "end-of-life" situations or chronic diseases necessitating intervention, even though the parents did not strongly consider the prognosis provided by the treating doctor, the biggest influence on the decision-making process came from the physician. Most parents opined that the doctor's opinion mattered more than anything else in considering the final treatment decision. ${ }^{25}$ Apart from the treating physician, other people who heavily influenced decision making included other family members and friends (especially those with disease-specific similar experiences), school staff, other parents with similar experiences (from support groups), etc. However, the most important person to influence the parent's decision is perhaps the child himself or herself. The child's preferences (particularly while considering injectable therapies) and the parent's goal for their child are the key factors influencing their decisions when it comes to discontinuing chronic therapy. In the study done by van Dongen and Kaptein, ${ }^{6} 37 \%$ of children using GH therapy felt anxious about the device used (needle and pain associated with injection). Similarly, $40 \%$ of the parents admitted that they had noticed an increase in reluctance 
to take GH treatment after the child entered puberty and 57\% welcomed the opportunity for a psychologist to give emotional support to them and their children. ${ }^{6}$

Parents often gather information regarding the disease status and therapeutic options (particularly for chronic illnesses) from multiple sources. This may include one or more health care providers (taking second opinion), other individuals in similar situations (established disease-specific support groups), and the Internet (Wikipedia and Google). Even though understanding the underlying medical condition and the implications of therapeutic intervention is essential and core to the decision-making process by the parents, often familial and emotional factors play a larger role than the opinion of the treating doctor/other individuals in many cases. Multiple studies have shown that the final decision taken by the parents is heavily influenced by their emotions, beliefs, and values in a variety of clinical scenarios. ${ }^{26}$ For example, feelings of guilt or a feeling of "failure as a parent" if they are not able to provide GH at an appropriate time due to financial constraints may influence their decision-making process. Also, the parent's final decision may be influenced by their faith, their personal beliefs, such as "destiny", "fate", or "karma", which leads to acceptance of the underlying medical condition or the proposed therapy for the same.

\section{Parent's perspective of the doctor's role}

In the pediatric decision-making process, the physicianparent relationship is one of the most important and influential factors. Hence, it is necessary to understand what the parent's expectations are and their perspectives of what the doctor should provide. As mentioned earlier in the "Parent's role in decision making" section, most parents prefer to be involved in the decision-making process to some extent at least, and they see the treating doctor as their close partner in arriving at a final decision. ${ }^{25}$ From the parent's perspective, the physician's primary role is to provide the parents and others involved in the decision-making process with accurate and reliable medical information that is necessary for them to arrive at a preference-sensitive final decision. This information may include precise and accurate medical information of the underlying disease condition, the treatment options available, the benefits and side effects of these options, the expenses to be incurred by the parents, the treating doctor's experience with similar cases, and finally, the doctor's opinion on the choice of therapy that is preferred. ${ }^{27}$

The study by van Dongen and Kaptein ${ }^{6}$ showed that contrary to the belief that a chronic condition such as $\mathrm{GH}$ therapy warrants active involvement of the parents, their actual involvement in the decision-making process as perceived by them was in fact much lesser than optimal. Parents did not feel that they were involved in the process of making treatment decisions. Half of all the respondents indicated that they did not have any freedom of choice between the devices. At the time of diagnosis and starting GH treatment, $68 \%$ of the parents were presented with just one GH device, whereas $32 \%$ were shown a minimum of two different types. In response to whether the parents felt they had freedom in the choice of device, $48 \%$ said that they felt they did not have freedom of choice, $9 \%$ indicated that they felt free to choose to some extent, and $43 \%$ answered that they felt fully free to choose a device. These data support the conclusion of lack of adequate and appropriate involvement of parents in the treatment choice for GH replacement.

Parents appreciate the information offered by the physicians and other health care providers and the opportunity they are given to partner with the doctor in deciding therapeutic options for their children. In certain instances, when the preference-sensitive decision is not the optimal choice, the parents perceive that the physician's role should be more important, and that the physician should in fact take the final decision, and that the parent's role is simply to follow that recommendation. However, they also recognize that the individual doctor's knowledge may be limited, and that, at least in some cases, their own decision-making ability is hampered by the doctor's insufficient disease-specific knowledge. ${ }^{28}$ Hence, there may be some conflict between the parent's desires and wants for appropriate medical information from the physician, and the physician's ability and knowledge to provide such information. The parents understand the need to obtain opinion from health care providers with expertise in the disease-specific field in order to maximally benefit from this parent-physician partnership.

\section{Interactions between parents and children}

Though children are not legally considered competent enough to take medical decisions on their own, decision-making roles exist for children who are age wise and developmentally appropriate. ${ }^{10}$ This is an aspect that is unique to the pediatric decision-making process because parents and children interact in different ways at different ages. While very young children have limited decision-making abilities, the adolescent child who is able to independently do other things in life may want to be more involved in the decision-taking process. ${ }^{29}$ Many observational studies have shown that most parents need help in determining when and how to include 
their child in the decision-making process. According to various studies, during acute illnesses where rapid decisions are needed, parents are less likely to involve their children in the decision-making process, and the children are often not in a position to influence the therapeutic intervention chosen. When it comes to management of chronic conditions, the child and his/her parents are more likely to interact with each other, and the child's opinion and desires may partly at least affect the treatment decision.

It was found that more involvement and participation from the child's side are likely to improve adherence to therapy. In the study done by van Dongen and Kaptein, ${ }^{6}$ $92 \%$ of the parents felt that self-administration by the child would give them and the child more freedom in their daily lives, and $65 \%$ felt a specially designed training course for the same would be beneficial when the child is around 10-11 years of age. How to interact with the child or what role the child is expected to play in the decision-making process largely depends on the child's intellectual and developmental ability to analyze the situation and voice his/her opinion. One way of including children is to ask them for their opinion and gather information from them that will prove to be useful for the parents to arrive at a final decision. Though parents say they prefer active involvement from their child in the decision-making process, it is not uncommon for them to filter out the information passed on to the child in an attempt to positively influence the decision preferred by the child and to ensure that it is concordant with the decision taken by the parents themselves. ${ }^{30}$ When surveyed separately, most children and parents tend to differ about their perceived role in the decision-making process, and this was particularly true among the adolescents and their parents.

\section{Clinical practice model for shared decision making}

The principles and importance of shared decision making are well documented in the literature but there is a lack of guidance and training about how to accomplish this approach in routine clinical practice. Even though shared decision making has been shown to have benefits, with better adherence to therapy and improved therapeutic outcomes, some clinicians still express doubt about this process. They feel that sometimes the patients do not want to be involved in the decision-making process, they lack the capability to arrive at the right decision or, they may end up making a "bad" or wrong choice. Some physicians feel that shared decision making is simply not practical, given the time constraints we are faced with. ${ }^{31}$ However, even when clinicians felt they were advocating the practice of shared decision making, at times, patient-experience surveys suggest that the parent or patient did not necessarily feel the same way. ${ }^{32}$ Hence, the first step toward a better model of shared decision making would be to ensure that the doctors and other health care providers understand and support the rationale of shared medical decisions.

Elwyn et $\mathrm{al}^{33}$ have proposed a model for shared decision-making process that can be easily incorporated into clinical practice (Figure 1). This model has three steps: 1) introducing choice; 2 ) describing options, usually by integrating the use of patient decision support; and 3) helping patients to explore preferences and finally make appropriate decisions. The first step called "choice talk" refers to making sure that the patients know there are reasonable options available for them to choose from. The second step called "option talk" refers to providing more detailed information about options, and the final step called "decision talk" refers to supporting

\begin{tabular}{|lll|}
\hline - Choice talk & - Option talk & - Decision talk \\
- Step back & - Check knowledge & - Focus on \\
preferences & \\
- Offer choice & - List options & - Elicit preferences \\
- Justify choice & - Describe & - Move to a decision \\
(preferences & options - explore & - Offer review \\
matter) & preferences & \\
- Check reaction & Harms and & \\
- Defer closure & - Provide patient \\
& decision support & \\
& - Summarize & \\
&
\end{tabular}

Figure I A clinical practice model for shared decision making. 
the parents in considering their preferences and deciding what is best. This model was built on the basis of previous work done in the field of shared decision making and by integrating various contributions. It is in accordance with good clinical practice habits and the principles of beneficence and justice. ${ }^{34}$

\section{Conclusion}

Shared medical decision-making process is becoming an important aspect of the therapeutic and healing process in medicine and assumes immense significance while treating patients with GH replacement, both in the adult and pediatric population. The decision to treat with GH need not be taken on an emergency basis as short stature is not a life threatening condition; hence patients can take time to think it over and come to a final decision. As health care providers, it is important that we not only assess the medical indication for GH replacement, assess the cost-benefit ratio for the individual patient, provide adequate information on efficacy and safety issues for the particular indication, but also learn to be sensitive to the patient's/parent's preferences, which are largely influenced by emotional and sociocultural factors.

\section{Disclosure}

The authors report no conflicts of interest in this work.

\section{References}

1. Blizzard RM. History of growth hormone therapy. Indian J Pediatr. 2012;79(1):87-91.

2. Raben MS. Treatment of a pituitary dwarf with human growth hormone. J Clin Endocrinol Metab. 1958;18:901-903.

3. Frasier SD. Human pituitary growth hormone (hGH) therapy in growth hormone deficiency. Endocr Rev. 1983;4:155-156.

4. Rubin RR, Peyrot M. Factors affecting use of insulin pens by patients with type 2 diabetes. Diabetes Care. 2008;31:430-432.

5. Growth Hormone Research Society. Consensus guidelines for the diagnosis and treatment of growth hormone (GH) deficiency in childhood and adolescence: summary statement of the GH Research Society. GH Research Society. J Clin Endocrinol Metab. 2000;85:3990-3993.

6. van Dongen N, Kaptein AA. Parents' views on growth hormone treatment for their children: psychosocial issues. Patient Prefer Adherence. 2012:6:547-553.

7. Charles C, Gafni A, Whelan T. Decision-making in the physician-patient encounter: revisiting the shared treatment decision-making model. Soc Sci Med. 1999;49(5):651-661.

8. Kasper Jf, Mulley Jr. AG, Wennberg JE. Developing shared decision making programs to improve the quality of health care. QRB Qual Rev Bull. 1992;18:183.

9. Singh J, Cuttler L, Shin M, Silvers JB, Neuhauser D. Medical decisionmaking and the patient: understanding preference patterns for growth hormone therapy using conjoint analysis. Med Care. 1998;36(8 Suppl):AS31-AS45.

10. Gabe J, Olumide G, Bury M. 'It takes three to tango': a framework for understanding patient partnership in paediatric clinics. Soc Sci Med. 2004;59(5):1071-1079.

11. Kon AA. The shared decision-making continuum. JAMA. 2010;304(8):903-904.
12. Fiks AG, Localio AR, Alessandrini EA, Asch DA, Guevara JP. Shared decision-making in paediatrics: a national perspective. Paediatrics. 2010;126(2):306-314.

13. Franck LS, Callery P. Re-thinking family-centred care across the continuum of children's healthcare. Child Care Health Dev. 2004;30(3):265-277.

14. Zikmund-Fisher BJ, Sarr B, Fagerlin A, Ubel PA. A matter of perspective: choosing for others differs from choosing for yourself in making treatment decisions. J Gen Intern Med. 2006;21(6):618-622.

15. AAP. Family-centred care and the paediatrician's role. Paediatrics. 2003;112(3 Pt 1):691-697.

16. Institute of Medicine. 100 Initial Priority Topics for Comparative Effectiveness Research. Available from: http://www.nationalacademies. org/hmd/ /media/Files/Report\%20Files/2009/ComparativeEffectivenessResearchPriorities/Stand\%20Alone \%20List $\% 20$ of $\% 20100 \% 20$ CER\%20Priorities\%20-\%20for\%20web.ashx. Accessed May 20, 2016.

17. Lipstein EA, Brinkman WB, Britto MT. What is known about parents' treatment decisions? A narrative review of paediatric decision making. Med Decis Making. 2012;32(2):246-258.

18. Gagnon EM, Recklitis CJ. Parents' decision-making preferences in paediatric oncology: the relationship to health care involvement and complementary therapy use. Psychooncology. 2003;12(5):442-452.

19. Merenstein D, Diener-West M, Krist A, Pinneger M, Cooper LA. An assessment of the shared-decision model in parents of children with acute otitis media. Paediatrics. 2005;116(6):1267-1275.

20. Tarini BA, Christakis DA, Lozano P. Toward family-centred inpatient medical care: the role of parents as participants in medical decisions. J Pediatr. 2007;151(6):690-695.

21. Cox ED, Smith MA, Brown RL. Evaluating deliberation in paediatric primary care. Paediatrics. 2007;120(1):e68-e77.

22. Angst DB, Deatrick JA. Involvement in health care decisions: parents and children with chronic illness. J Fam Nurs. 1996;2(2):174-194.

23. Pyke-Grimm KA, Stewart JL, Kelly KP, Degner LF. Parents of children with cancer: factors influencing their treatment decision making roles. J Pediatr Nurs. 2006;21(5):350-361.

24. Daniel E, Kent G, Binney V, Pagdin J. Trying to do my best as a mother: decision-making in families of children undergoing elective surgical treatment for short stature. Br J Health Psychol. 2005;10(Pt 1): 101-114.

25. Fiks AG, Hughes CC, Gafen A, Guevara JP, Barg FK. Contrasting parents' and pediatricians' perspectives on shared decision-making in ADHD. Pediatrics. 2011;127(1):el88-e196.

26. Higgins SS, Kayser-Jones J. Factors influencing parent decision making about pediatric cardiac transplantation. J Pediatr Nurs. 1996;11(3):152-160.

27. Bradbury ET, Kay SP, Tighe C, Hewison J. Decision-making by parents and children in paediatric hand surgery. Br J Plast Surg. 1994;47(5):324-330.

28. Slatter A, Francis SA, Smith F, Bush A. Supporting parents in managing drugs for children with cystic fibrosis. Br J Nurs. 2004;13(19): $1135-1139$.

29. La Greca AM, Prinstein MJ. Peer group. In: Silverman WK, Ollendick TH, editors. Developmental Issues in Clinical Treatment of Children. Needham Heights, MA: Allyn \& Bacon; 1999:171-198.

30. Miller VA. Parent-child collaborative decision making for the management of chronic illness: a qualitative analysis. Fam Syst Health. 2009;27(3):249-266.

31. Zikmund-Fisher BJ, Couper MP, Singer E, et al. The DECISIONS study: a nationwide survey of United States adults regarding 9 common medical decisions. Med Decis Making. 30(5 Suppl):20S-34S.

32. Coulter A. Do patients want a choice and does it work? BMJ. 2010;341:973-975.

33. Elwyn G, Frosch D, Thomson R, et al. Shared decision making: a model for clinical practice. J Gen Intern Med. 2012;27(10):1361-1367.

34. Wear S. Informed Consent: Patient Autonomy and Clinician Beneficence within Health Care. Washington DC: Georgetown University Press; 1998. 
Research and Reports in Endocrine Disorders is an international, peerreviewed, open access journal publishing original research, reports, reviews and commentaries on all areas of endocrinology, endocrine disorders and therapeutic interventions. The manuscript management system is completely online and includes a very quick and fair peer-review system. Visit http://www.dovepress.com/testimonials.php to read real quotes from published authors.

Submit your manuscript here: https://www.dovepress.com/research-and-reports-in-endocrine-disorders-journal 